NBER WORKING PAPER SERIES

\title{
ARE CONSUMERS ATTENTIVE TO LOCAL ENERGY COSTS? EVIDENCE FROM THE APPLIANCE MARKET
}

Sébastien Houde

Erica Myers

Working Paper 25591

http://www.nber.org/papers/w25591

\author{
NATIONAL BUREAU OF ECONOMIC RESEARCH \\ 1050 Massachusetts Avenue \\ Cambridge, MA 02138 \\ February 2019
}

We would like to thank Meredith Fowlie, Christopher Knittle, Richard Newell, Ryan Kellogg, Kochiro Ito, in addition of numerous seminar participants. The U.S. Department of Energy and the National Science Foundation provided funding for this project through the NBER Economics of Energy Market program. This research is also part of the activities of SCCER CREST, which is financially supported by the Swiss Commission for Technology and Innovation (CTI) / Innosuisse. The views expressed herein are those of the authors and do not necessarily reflect the views of the National Bureau of Economic Research.

NBER working papers are circulated for discussion and comment purposes. They have not been peer-reviewed or been subject to the review by the NBER Board of Directors that accompanies official NBER publications.

(C) 2019 by Sébastien Houde and Erica Myers. All rights reserved. Short sections of text, not to exceed two paragraphs, may be quoted without explicit permission provided that full credit, including (C) notice, is given to the source. 
Are Consumers Attentive to Local Energy Costs? Evidence from the Appliance Market

Sébastien Houde and Erica Myers

NBER Working Paper No. 25591

February 2019

JEL No. D12,D83,Q41,Q50

\begin{abstract}
$\underline{\text { ABSTRACT }}$
We estimate whether consumers respond to local energy costs when purchasing appliances. Using a dataset from an appliance retailer, we compare demand responsiveness to a measure of energy costs that varies with local energy prices versus purchase prices. We strongly reject that consumers are unresponsive to local energy costs under a wide range of assumptions. These findings run counter to the popular wisdom, which motivates energy standards, that energy costs are a shrouded attribute. Capital investments are an important channel for electricity demand response and may explain some of the large differences between short and long run electricity price elasticities.
\end{abstract}

Sébastien Houde

ETH Zurich

Department of Management, Technology, and Economic

Centre for Energy Policy and Economics

Zurichbergstrasse 18, 8092 Zurich

shoude@ethz.ch

Erica Myers

University of Illinois at Urbana-Champaign

and E2e

ecmyers@illinois.edu 


\section{Introduction}

Policymakers are increasingly relying on behavioral insights to design programs to alter consumer choices in ways that might improve market efficiency. Consumers make systematic mistakes in their choices for a wide range of products, such as health care plans (Abaluck and Gruber 2011; Kling et al. 2012; Handel and Kolstad 2015), mutual funds (Barber et al. 2005), schools (Jensen 2010), and which foods to consume (Bollinger et al. 2011), among many others. Whether and how we should regulate markets when consumers are prone to mistakes has become an important and sometimes controversial topic (Allcott and Sunstein 2015; Mannix and Dudley 2015).

In the energy context, policymakers have long argued that consumers undervalue energy operating costs, which has been the primary rationale for energy efficiency standards and energy labeling programs adopted in the 1980's in the U.S. and elsewhere. A long held view is that markets for energy-intensive durables, such as cars and appliances, may not operate efficiently if consumers purchase products that were "too energy intensive" (Hausman and Joscow 1982). Therefore, limiting choices through standards and empowering consumers with information labels may have the potential to improve welfare through steering consumers to make better choices and by reducing externalities.

This paper asks how responsive U.S. consumers are to energy operating costs when purchasing household appliances. Apart from being a critical input for energy policy design, investigating consumers' response to energy operating costs in the U.S. appliance sector provides an important case study for the design of regulations and nudges in complex choice environments. The popular wisdom is that energy costs are a "shrouded" attribute of appliances, although some relevant information is readily available in this decision context due to the presence of two energy labels: the mandatory EnergyGuide label and the voluntary Energy Star label (Figure 1). These labels are examples of imperfectly targeted nudges (Allcott and Knittel 2019) designed to help consumers but that may have unintended consequences. Sallee (2014) and Davis and Metcalf (2016) highlight that the EnergyGuide label provides estimates of energy operating costs that rely on national averages, 
but substantial variation exists at the local level, which may induce consumers to under- or overinvest in energy efficiency. Houde (2018) shows that the Energy Star label, which only provides a binary signal about the most energy-efficient products in the marketplace, is a very coarse piece of energy information that may crowd out efforts to compute energy operating costs. Both types of labels exemplify the difficulties of designing information-based policies: simple and salient pieces of information may still mislead consumers, whereas detailed and complex information might be simply ignored. Similar issues arise in contexts such as consumer financial protection (Campbell et al. 2011), health insurance (Handel and Kolstad 2015), and nutrition (Downs et al. 2009), to name a few, where policymakers require information disclosure to address potential consumer mistakes.

An important element of our analysis is that we focus on estimating consumer responsiveness to their local energy operating costs. In particular, our empirical strategy provides evidence that consumers can overcome imperfectly targeted information in the U.S. appliance market and rely on local average electricity prices to form estimates of appliances' energy operating costs when making a purchase decision. It is not immediately straightforward for consumers to incorporate local electricity prices into appliance decisions since monthly electricity bills are often complex and provide only aggregated usage information, making it difficult to map particular end uses to costs.

We use a unique administrative data set from a large national appliance retailer with individual transaction data on the timing and price paid for each model sold. Since we know the location of each branch of the retailer, we can match county-specific annual electricity prices to each transaction. We focus on refrigerators, which offer two advantages. First, since refrigerators are plugged in continuously over their lifetime, it is straightforward to model operating costs, and abstract away from households' utilization decisions. Second, refrigerators consume a large amount of energy and there is rich variation in prices and expected energy consumption across models, which allows us to identify households' behavioral responses.

We employ a widely used test of consumer misperception: to compare the demand response to potentially misperceived costs (e.g. sales tax, shipping and handling fees, highway tolls, or 
energy operating costs), versus salient, correctly perceived purchase costs. ${ }^{1}$ Unlike many demand estimation exercises, the pricing scheme of the appliance retailer results in variation in purchase prices that is plausibly exogenous to local market conditions. As we describe in detail in what follows, the retailer has a national pricing algorithm that induces model-specific idiosyncratic price variation. We exploit this variation and account for potential correlated demand shocks using a rich set of fixed effects.

We estimate demand responsiveness to local energy operating costs using variation in relative operating costs among models coming from electricity price differences across utilities and over time. We show that these electricity price differences are largely driven by exogenous variation in the fuel costs. The fine grained nature of our data allow us to control for county-by-time specific movements in appliance demand, which allows us to disentangle the effect of energy operating costs on product choice from confounding market conditions which affect the probability of buying an appliance at all.

Counter to the popular wisdom, that local energy costs are a "shrouded" attribute of appliances (e.g., Auffhammer 2017), our findings strongly reject that consumers are unresponsive to appliance operating costs under a wide range of lifetime and discount rate assumptions. Our preferred estimates suggest that consumers are indifferent between $\$ 1.00$ in discounted future energy costs and $\$ 0.82$ in purchase price. These results are consistent with recent work in car and housing markets, where it is generally considered much easier to map fuel consumption to its cost than for household appliances. People tend to know how much it would cost to drive from one place to another in car, given many households purchase gasoline one or more times a week and that gasoline prices are prominently posted at gas stations. Heating costs appear seasonally and constitute a big jump in natural gas bills compared to baseload water heating and cooking consumption, making most people aware of how much it costs to heat their home. Recent estimates of implied discount rates for automobile and house purchases range between 3\% and 15\% (Busse et al. 2013; Allcott and ${ }^{1}$ See for example, shipping and handling fees (Hossain and Morgan 2006), sales tax (Chetty et al. 2009), highway tolls (Finkelstein 2009). 
Wozny 2014; Sallee et al. 2016; Grigolon et al. 2018; Myers 2018), which is in line with our valuation ratio. $^{2}$ Overall, our findings suggest that consumers are attentive to local energy operating costs, and do not simply rely on information about national averages, which is readily available in this context.

Previous work quantifying consumer attention to energy operating costs in the context of appliances has been mixed, with some studies finding that consumers substantially discount future energy costs (e.g., Hausman 1979; Dubin and McFadden 1984) and others finding more modest undervaluation (e.g., Rapson 2014; Houde 2018). These studies have relied on variants of a discrete choice model and have exploited primarily cross-sectional variation in energy prices. While there is rich cross-sectional price variation in the U.S., it may be correlated with systematic differences in demographics or consumer preferences across regions, thus biasing these types of estimates.

Jacobsen (2015) is one example of a recent study that attempts to address this issue by using state level panel data to assess the effect of energy prices on Energy Star market shares. He finds very little evidence that energy prices affect the market share of Energy Star appliances. The Energy Star certification is, however, an imperfect proxy for energy operating costs because the certification requirement varies with product class and is thus not perfectly correlated with energy consumption. Moreover, consumers may value Energy Star models for reasons other than energy savings (Newell and Siikamaki 2017; Houde 2018).

Our work thus provides the first estimates of consumer attentiveness to appliance energy operating costs by exploiting rich panel data. In the spirit of recent approaches in the context of cars and housing (e.g., Busse et al. 2013; Allcott and Wozny 2014; Grigolon et al. 2018; Myers 2018), we estimate average responsiveness with microdata which allows us to control for region-specific trends in preferences, removing many of the factors that might be correlated with electricity price that confound approaches using cross-sectional or more aggregated data.

${ }^{2}$ Our framework also allows to compute an implied discount rate, which corresponds to approximately $8 \%$ in our preferred specification. 
Our findings show that higher local electricity prices lead to the adoption of more energy-efficient appliances. These results contribute to our understanding of electricity price demand response. While consumers are relatively inelastic in the short run, they do change their consumption in response to changes in their local average electricity prices. Ito (2014) estimates a price elasticity of -0.07 to -0.09 in the 1 to 4 months following a price change. Deryugina et al. (2017), find that consumers are much more demand responsive to electricity price changes given more time to adjust, with a long run elasticity estimates between -0.31 and -0.35 . Our results suggest that one important channel for electricity demand response is through capital investments, which may explain some of the differences between short and long run elasticities. These investments are an important margin to consider when designing energy and climate policies, which will have heterogeneous impacts on local electricity prices.

This paper proceeds as follows. Section 2 describes the data, Section 3 details the empirical framework, Section 4 describes the estimates of consumer inattention to energy operating costs, and Section 5 concludes.

\section{Data}

We use transaction level data from a major U.S. appliance retailer, which include all transactions for 2008-2012 that involve full-size refrigerators. Each transaction has information about the price paid, zip code of the store location, refrigerator model number, and an identifier tracking consumers making multiple purchases with the same credit card. During the sample period, we observe several million refrigerator purchases across all 50 states. For our analysis, we first exclude online sales, which represent a small fraction of the sales during the sample period. We also exclude purchases made by renters, which also represent a small percentage $(<2 \%)$. Finally, we restrict the sample to transactions where we observe only one purchase of a full-size refrigerator by household identifier. This corresponds to approximately $68 \%$ of the sample. The latter criterion is a conservative way to identify transactions made my households in the sample. Our goal is to exclude transactions made 
by contractors, landlords, or governmental entities that may be subject to different incentives when investing in energy-efficient appliances. For example, they may not have to pay for the electricity operating costs of the appliances they purchase.

The purchase price we use in our analysis is the actual retail price paid by the consumer. We also observe the manufacturers' suggested retail prices, sales taxes paid on each transaction, and an indicator variable that specifies whether the retail price paid for a particular transaction corresponded to a promotional price. An important institutional feature that we exploit in our analysis is the fact that the retail prices are determined by the retailer at the national level using a dynamic pricing algorithm. The pricing strategy results in rich variation over time and appliance models, but not across stores. In particular, the price of each refrigerator model is subject to weekly variation, which is model specific and not perfectly correlated across brands.

Figure 2 shows the idiosyncratic variation that the dynamic pricing algorithm induces. Each panel plots time series of retail prices for four different refrigerator models. For illustration purpose, we focus on the two most popular models of two brands. Although, the patterns are similar across other models and brands. To create the figure the data are aggregated to the model-week-zip code level. We first normalized retail prices by removing model-specific fixed effects. We then computed the median, the $25^{t h}$ percentile and the $75^{\text {th }}$ percentile at the model-week level. The goal of comparing these three time series is to show that there is little variation across regions for a given model due to the national pricing strategy. For each panel, we observe that for most weeks, the $25^{\text {th }}$ and the $75^{\text {th }}$ percentiles exactly coincide with the median retail prices - i.e. there is no variation across regions. Variation over time is, however, important. From week to week, we see price changes of the order of $10 \%$. Another important take away from Figure 2 is that the rich weekly variation appears to not be correlated within brand. We show this formally by plotting normalized price without week-of-sample fixed effects interacted with brand dummies (the blue dashed line). These fixed effects remove all the time varying demand shocks that might impact the different brands in the U.S. refrigerator market. The fact that these residual prices closely 
follow the normalized price of each model shows that the pricing algorithm induces model-specific variation, which is independent of the brand.

Further, the variation appears to be independent to demand shocks for particular refrigerator features. In Table 2, we show the change in price with respect to the mean after controlling for not only brand-by-week fixed effects, but also Energy Star-by-week fixed effects, and other attributeby-week fixed effects (i.e. size-by-week, and freezer location-by-week fixed effects). These various controls remove little variation compared to the variation observed in normalized prices. This suggests that the pricing algorithm provides credible exogenous variation in retail prices, which is uncorrelated with shifts in demand.

We create a measure of annual energy cost for each refrigerator purchase using the manufacturer reported kWh/year consumption multiplied by the county-level annual average electricity price. County level electricity prices are constructed using the Energy Information Administration (EIA) form 861, which reports revenue and quantity of electricity consumed by residential consumers. We divide revenue by quantity sold to create a measure of average electricity price for each utility operating in the U.S. The EIA also provides information on which utilities serve each county, allowing us to map average energy prices to the county-level. If a county is served by more than one utility, we take an average of the prices for each utility serving that county.

In our estimation, we exploit variation in the relative energy operating costs among models coming from electricity price differences across utilities as well as changes in prices over time. Areas with higher electricity prices at particular points in time will have larger differences in relative operating costs than places that have lower electricity prices at particular points in time. Figures 3 and 4 give a sense of this variation. Figure 3 shows the mean sales-weighted annual electricity price for each state in a U.S. census division. Each of the 9 plots represents a U.S. census division and each line on the plot represents a state in that census division. It is clear from this figure that prices vary substantially regionally, with the highest prices in New England (above $\$ 0.15 / \mathrm{kwh}$ on average) and lowest prices in the Midwest and the South (less than $\$ .10 / \mathrm{kwh}$ on 
average). There is also some variation in prices over time, where some states experience increases over the study period, while others experience decreases.

Figure 4 displays density plots of prices and lifetime energy costs. The first panel shows the distribution of prices paid in our sample. Almost all models sold are less than $\$ 2000$, though there is some density for high price models (> \$5000). The average price paid is $\$ 1263$ (Table 1$)$. The second panel shows how the the distribution of the life time energy costs vary across places with higher or lower electricity prices. We display the distribution for the 10th, 50th, and 90th percentile of county electricity prices. To calculate the life time energy cost of each model, we sum the annual energy cost over an expected lifetime of 18 years, using a $5 \%$ discount rate. ${ }^{3}$ The average annual energy cost is $\$ 61$ for the whole sample (Table 1). But there is substantial variation across regions. Mean lifetime costs vary from $\$ 555$ for the 10 th percentile of energy price to $\$ 1000$ for the 90 th percentile. The third panel displays the distribution of the ratio of lifetime cost to purchase price. The mean ranges from 0.44 at the 10 th percentile of energy price to 0.79 at the 90 th percentile. Therefore, operating costs can be thought of as a significant fraction of the lifetime costs of the appliance.

In the U.S. appliance market, another potential determinant of purchases are consumer rebates for models that are certified by the Energy Star program. During the sample period, two types of Energy Star rebates were offered. First, several electric utilities offered rebate programs as part of their demand-side management portfolio. The DSIRE database collects all information about utility rebate programs. Using these data, we identified all rebate programs that apply to full-size refrigerators and constructed time series of utility rebates at the year-county level. Utility rebate programs were present in 129 different counties during the period 2008-2012. In those counties, the rebate amount ranged from $\$ 10$ to $\$ 250$, with a mean of $\$ 74$. In addition to utility rebate programs, state governments also offered rebates for Energy Star products during that period. The State Energy Efficiency Appliance Rebate Program (SEEARP) was funded as part of the stimulus

\footnotetext{
$\overline{3}$ These lifetime and discount rate values are used by the Department of Energy (DOE) in setting appliance
} standards 
package of the American Recovery Act. This program led to generous rebates for Energy Star certified products from 2010 through 2011. Houde and Aldy (2017) collected data on the level and timing of the rebate programs offered by each state, which we use for this analysis. In several states, these programs were short-lived and lasted a few weeks, and even a few days in some rare instances. We thus constructed measure of SEEARP rebate at the state-week level. These rebate programs have substantial variation across states and time - 44 states offered a rebate targeting full-size refrigerators with a mean rebate amount of $\$ 128$.

For our main analysis, we aggregate the transaction level data at the model-week-zip code level. For each appliance model, we create time series of sales and retail prices. We do not observe store inventories, and not all models sell in every zip code in every week. We impute choice sets using the first and last sales of each refrigerator model in each location (i.e., zip code). That is, we assume that this model was available between those two sale events period at this particular location. The time series of sales have a large number of zeros, which correspond to weeks where a model was available but did not sell. The overall sample used for the estimation has 18,725,640 unique combinations of refrigerator models, weeks, and zip codes. We observe 2,520 different models during the period 2008-2012. Table 1 provides additional summary statistics for the main variables used in our estimation.

The price variable that we use in our regressions is the weekly retail price inclusive of all local sales taxes. The sales tax rates are computed using our data and correspond to zip code-yearly averages. For our estimation, we drop 1,241 observations ( $>0.01 \%$ of the sample) without information about sales taxes. 


\section{Empirical Strategy}

\subsection{Main Specification}

In order to estimate the average demand response to changes in both purchase price and electricity costs, our preferred specification is as follows.

$$
q_{j r t}=\eta P_{j r t}+\theta E_{j r t}+\tau E S_{j t}+\phi \text { Rebate }_{j r t}+\gamma_{j}+\text { Brand }_{j} \times \text { Week }_{t}+\text { County }_{r} \times \text { Att }_{j}+\xi_{r t}+\varepsilon_{j r t}
$$

We regress the quantity $(q)$ sold of product $j$ in zip code $r$ and week $t$ on the product's price $\left(P_{j r t}\right)$, the product's annual energy cost $\left(E_{j r t}\right)$, the Energy Star certification status $\left(E S_{j t}\right),{ }^{4}$ rebates offered for Energy Star certified products $\left(\right.$ Rebate $\left._{j r t}\right)$, product fixed effects $\left(\gamma_{j}\right)$, brand dummies interacted with week-of-sample $\left(\operatorname{Brand}_{j} \times W e e k_{t}\right)$, county fixed effects interacted with product attributes $\left(\right.$ County $\left._{r} \times A t t_{j}\right)$, and county-by-time fixed effects $\left(\xi_{r t}\right)$.

We include product fixed effects to control for the time invariant, unobservable characteristics of a particular product, which make it more or less attractive. The brand-by-week fixed effects capture any demand shifts for particular brands over time due to factors such as advertising campaigns. Therefore, the coefficient $\eta$ is identified from the variation in modelspecific prices generated by the retailer's dynamic pricing algorithm. To the extent that the variation in the national price is determined by supply-side shocks and other idiosyncratic drivers, it will be exogenous to local market conditions. If the variation is determined by

${ }^{4}$ The Energy Star certification status of a large number of refrigerator models changed in 2008 due to a more stringent requirement. Models that did not meet the certification requirement had to be decertified. 
demand-side drivers, it could create endogeneity and bias our demand estimates. We explore this possibility by testing the robustness of our estimates to various controls for shifts in demand, as we describe further in what follows.

County-by-time fixed effects control for the mean probability of purchasing any of the available products in a given time period in a given county. In this way, we are flexibly controlling for trends in preferences for the outside option, without having to make explicit assumptions about local market size or the level of utility from the outside option. The outside option in this context refers to the decision: 1) not to purchase a refrigerator in this particular week, or 2) to purchase a refrigerator at another retailer. In addition to capturing the variation in the local market size over time, county-by-time fixed effects also capture local trends affecting the retailer. Our main specification uses county-by-year fixed effects. We also show that using finer time variation in our controls, i.e. county-by-week FE, makes little difference since the variation in electricity price is at the county-year level.

Since county-by-year is the level of our electricity price variation the model estimates the effects of differences in annual energy costs and purchase price on the probability of purchasing a particular product, given that the customer has decided to buy a refrigerator in a particular zip code in a particular year. The remaining variation in annual energy operating cost comes from the relative energy cost differences among products in a given county in a given year, where the relative energy cost differences will be larger in counties with high electricity prices than in counties with low electricity prices. Therefore, we are estimating effect of energy operating costs on product choice while controlling for confounding local market conditions affecting the probability of buying an appliance at all.

One concern with the variation in relative energy costs we are using in our model is that preferences for energy-related attributes are correlated with local electricity prices. This 
correlation may arise for a variety of reasons. High income households might prefer larger refrigerators and live in regions subject to higher electricity prices. Moreover, in regions with high electricity prices such as New England and California, electric utilities, retailers, and local governments may advertise energy-efficient products more, especially Energy Starcertified products.

In order to control for region-specific preferences for energy-related refrigerator features we interact county dummies with several refrigerator attributes (denoted County $\times$ Att C $_{j}$. Specifically, we interact county dummies with Energy Star certification status as well as the two attributes that induce the most variation in refrigerators' energy use: 1) overall volume and 2) freezer location. We explore whether there is any remaining endogeneity in energy costs after including these controls using an instrumental variables approach, described in the next section.

Finally, we also control for rebates offered for Energy Star certified products $\left(\right.$ Rebate $\left._{j r t}\right)$, which may make Energy Star-certified products more attractive. Rebates vary across regions and time, and thus capture time-variant demand for certified products that is not captured by the refrigerator attribute-by-county fixed effects.

\subsection{Robustness Checks}

In addition to our main specification, we perform three other estimations to probe the robustness of our results: 1) a sensitivity analysis to the inclusion of several fine-grained fixed effects that capture shifts in demand to address the potential endogeneity of the retailer's national pricing algorithm, 2) an instrumental variable approach to address endogeneity and measurement error in energy costs, and 3) a Poisson estimation that addresses potential model mis-specification with a linear model due to a large number of zero sales. 


\subsubsection{Endogeneity of Retail Prices}

As mentioned above, if the retailer's national pricing algorithm is determined by aggregate shifts in demand for particular models or types of appliances, it could potentially bias our estimates. In order to explore this possibility, we estimate models that include attribute by week fixed effects. In particular, we interact Energy Star status, an indicator for fridge size (adjusted volume smaller than $<29 \mathrm{cu}$. ft.), and indicators for model type (i.e. top freezer, side by side refrigerator, or bottom-freezer) with week fixed effects. These fixed effects will capture trends in demand for particular model features. If most of the variation in the retailer's pricing algorithm is driven by shifts in demand, inclusion of these fixed effects will soak up a lot of the variation in purchase price and affect the coefficient estimates of $\eta$. If $\eta$ changes little, it is suggestive that the variation in the national pricing algorithm is driven by supply-side or other idiosyncratic drivers, which are exogenous to change in demand over time.

\subsubsection{Endogeneity and Measurement Error of Energy Costs}

While the county fixed effects interacted with energy-related attributes may control for some of the potential endogeneity between preferences for energy efficient products and local electricity prices, we address the issue more rigorously using an instrumental variable approach. Following Kahn and Mansur (2013), we construct instruments for county-level energy prices using the product of the local utility's capacity shares of coal, oil and gas-fired power plants and their respective annual average fuel price. We use data from EIA form 860 to construct the shares. We use shares from 2007, the year before our sales data begin, so that their values are pre-determined. We use the crude oil WTI spot price for petroleum plants and the annual Henry Hub contract 1 prices for natural gas plants. For coal plants, we 
use the national average coal price from EIA. We then calculate a single generation-weighted fuel price for each county by averaging prices across any utilities serving that county.

Using this instrument, the identifying variation in electricity price is coming from the underlying fuel price variation. This variation is driven by national and global economic trends, rather than by county or state specific policies. Therefore, the only way fuel price variation can affect local appliance selection is through higher or lower electricity prices due to the pre-determined generation mix.

This instrumental variables approach not only addresses the potential endogeneity between energy efficiency preferences and local electricity prices, but the issue of measurement error as well. Since we constructed our county-level electricity price as an average price for the utilities that serve a particular county, there will be some measurement error in the

calculated operating costs for individual purchases. Another potential source of measurement error is that we use the average county price of the county in which the appliance was purchased, which may differ in some cases from the county in which the consumer lives. This type of classical measurement error could attenuate our estimates of the coefficient on operating cost, and bias our estimates of responsiveness to energy costs towards zero. To investigate the role of measure error, we also examine the effect of using state-level average prices, which may have less measurement than county-level average prices.

\subsubsection{Model Misspecification}

In addition, we estimate attention to energy costs using a Poisson regression model. The Poisson estimation assumes a log-linear relationship, which may more accurately reflect the relationship between prices and quantities purchased. If so, it is better to model the conditional expectation of the dependent variable directly rather than applying a transformation 
to the dependent variable. Simply taking the log of sales counts (y) is not possible, since the value is zero for a non-trivial fraction of our data (Table 1). We could apply other trans-

formations that are defined for all $y \geq 0$, such as $\log (1+y)$, but it is not obvious how to recover $E(y \mid \mathbf{x})$ from a linear model for $E(\log (y+1) \mid \mathbf{x})$. Like OLS, which is consistent and asymptotically normal even if the normality assumption is violated, Poisson has the desirable property that quasi-maximum likelihood estimation recovers consistent, asymptotically normal coefficient estimates even if the Poisson distribution does not hold and standard errors can be adjusted for violations of the Poisson variance assumption that the variance is equal to the mean (Wooldridge 2010). We also use Poisson because unlike other count models, e.g., negative binomial, we are able to efficiently estimate models with high-dimensional fixed effects using the algorithm proposed by Guimaraes and Portugal (2011).

\subsection{Interpretation of Model Parameters}

The empirical test of consumer responsiveness in this paper asks how consumers trade off purchase price with energy costs. Absent any bias, consumers would be indifferent between an additional dollar of purchase price and an additional present discounted dollar of energy expenditure. The coefficient on annual energy cost, $\theta$, reflects how a $\$ 1$ change in annual energy operating costs affects sales, or more specifically the probability of a purchase. We measure consumer responsiveness as the ratio between a the effect of a $\$ 1$ change in lifetime energy operating costs on demand and the effect of a $\$ 1$ change in purchase price. In order to estimate lifetime operating costs, we need to make assumptions about: 1) how consumers sum and discount future operating costs, 2) consumers' expectations about future annual operating costs, 3) the lifetime of the appliance, and 4) consumers' discount rate.

One feature of our approach is it is straightforward for analysts to apply different assumptions for the lifetime cost parameters to judge consumer bias based on our reduced 
form estimates of consumer responsiveness to price and energy costs. In what follows, we describe our preferred parameter assumptions and the range we consider around them for sensitivity analysis.

For our analysis, we assume that consumers discount future costs using the exponential model of intertemporal choice and believe prices follow a random walk so that today's prices are the best predictor of tomorrow's prices. ${ }^{5}$ For the lifetime of the appliance, we use 18 years, and for the discount rate we use 5\%; both of these values are used by the Department of Energy (DOE) in setting appliance standards. In addition, we show sensitivity of our responsiveness measure to discount rates ranging from $2 \%$ to $10 \%$ and to lifetimes of 10,15 , or 20 years.

Assuming that consumers form time-invariant expectations about the annual operating electricity expenditure, the lifetime energy operating cost $\left(L C_{j}\right)$ for the durable $j$ is given by:

$$
L C_{j r t}=\sum_{t=1}^{L} \rho^{t} E_{j r t}
$$

where $L$ is the lifetime of the durable (18 years), $\rho=1 /(1+r)$ is the discount factor with discount rate $r$, and $E_{j r t}$ is the product of the electricity price paid by a household in region $r$ at time $t$ and the manufacturer's expected annual electricity consumption for durable $j$. In the estimation model specified by Equation 3.1, the coefficient on annual energy cost relates to the discount factor and marginal utility of income as follows:

\footnotetext{
${ }^{5}$ Anderson et al. (2013) finds that consumers believe that gasoline prices follow this type of pattern. Another possibility is that consumers use information from futures markets to make projections about electricity prices going forward. However, forward curves rarely deviate substantially from spot prices for major fuels. Therefore, even if consumers were and paying attention to trends in futures prices, their beliefs about fuel prices going forward would not differ significantly from no-change beliefs (Myers 2018).
} 


$$
\theta=\eta \cdot \rho \cdot \sum_{t=1}^{L} \rho^{t} E_{j r t}
$$

Give our parameter assumptions, the average measure of responsiveness to energy costs, also referred as the valuation ratio (Allcott 2013), is:

$$
m=\theta / \eta \cdot \rho \cdot \frac{1-\rho^{L}}{1-\rho} .
$$

\section{Results}

\subsection{Main Estimation}

Table 3 displays the results from the estimation of our main specification. Columns I through III show the impact of additional controls, where Specification IV corresponds to our preferred specification described by Equation 3.1. Rows 1 and 2 display the coefficient estimates for the product purchase prices and annual energy costs, respectively. Row 3 shows the estimate of the average consumer responsiveness to energy costs (the valuation ratio: $m$ ) using a 5\% discount rate and 18 years appliance lifetime. All specifications control for product fixed effects, Energy Star certification status, and Energy Star rebates.

The first column shows the results from an estimation including county fixed effects and week-of-sample fixed effects and the second column shows results from an estimation with county-by-year fixed effects, and with similar controls otherwise. When county fixed effects are not interacted with a time dimension, the coefficient on energy costs is statistically significant, but suggests a large degree of undervaluation of energy costs, where $m=0.27$. In Specification II, the coefficient on energy costs is more than three times larger than 
in Specification I, and $m=0.95 .{ }^{6}$ The large difference between Specifications I and II suggests that variation in local energy prices is potentially correlated with local market conditions, which affects refrigerator demand. Specifications controlling for county fixed effects uninteracted with time confound the effect of energy cost on appliance choice with its effect on the probability of buying an appliance at all.

One major advantage of our administrative data set is that we are able to use a research design that disentangles the effect of energy prices on product choice from confounding market conditions. County-by-year fixed effects control for the average probability that an appliance will be purchased in a county in a given year. The remaining energy cost variation comes from the relative variation in operating costs between high and low energy consuming appliances. This variation allows us to control for region-specific preferences for energy efficiency and exploit the fact that counties with high electricity costs in a given year have higher variation in operating costs for the same available models than counties with low electricity costs at a given point in time.

The estimation in column III includes county fixed effects interacted with the Energy Star certification status and with other energy-related attributes (i.e., dummies for large refrigerators and freezer location). Under this specification, the absolute magnitude of the coefficient on annual energy costs is reduced relative to Specification II such that the valuation ratio is now $m=0.89$. This suggests that local energy prices may be correlated, albeit weakly, with preferences for energy-related attributes. We explore any remaining endogeneity of the local electricity prices further with our instrumental variable approach described above. In our preferred specification, column IV, we include brand-week-of-sample fixed effects, instead of only week-of-sample fixed effects. This has a small impact on the coefficient of purchase

${ }^{6}$ In the Appendix (Table A2, Specification I), we show that county-by-week produces similar results to Specification II. 
price and the average measure of responsiveness is $m=0.82$, which suggests that the modelspecific variation in purchase price is not strongly correlated with brand-level strategies, as we previously demonstrated in Section 2 .

\subsection{Robustness Checks}

In Table 4, we examine the sensitivity of our preferred estimates to the inclusion of controls for shifts in demand for refrigerator attributes. In Specification I, we include Energy Star indicator-by-week fixed effects, and in Specification II, we include Energy Star indicator-byweek, refrigerator size-by-week, and freezer location (i.e. top, bottom, or side-by-side)-byweek fixed effects. These fixed effects control for any changes in demand for these attributes over time. The coefficient on purchase price is reduced compared to our preferred Specification IV in Table 3. This leads to an increase in the valuation ratio but the differences are not statistically significant at the $5 \%$ level. This confirms that exploiting the model-specific idiosyncratic variation induced by the retailer's pricing algorithm provides a credible source of identification.

In Table 5, we address measurement error and any remaining endogeneity in our constructed measure of local energy costs by implementing the instrumental variable strategy described earlier. The utilities for which we constructed fuel shares using EIA form 860 did not perfectly map to all of the counties in our sample, so we perform the IV approach on a subsample of our data (about $80 \%$ of the full sample). In Specification I, we estimate Equation 3.1 on this subsample of data using OLS and in Specification II, we estimate the model using two-staged least squares (2SLS).

The results from Specification I show that limiting our sample has little impact on the results from our preferred specification $(m=0.83)$, indicating that the counties for which 
we were able to construct the fuel price instrument were representative of our full sample. The coefficient on energy cost in the 2SLS estimation (Specification II) is larger and also less precisely estimated than in Specification I. It is, however, not statistically distinguishable from the OLS estimates. Altogether, this suggests that our county-level fuel prices are highly correlated with the fuel price instrument (see first-stage results in Table A1). Therefore, given the controls in our model, the identifying energy cost variation appears to be driven by the pre-determined electric generation fuel mix and exogenous supply side shocks to fuel prices. ${ }^{7}$

Table 6 presents the results for the Poisson regressions. We present two specifications with a parsimonious set of fixed effects to accommodate the estimation. In Specification I, we control for product fixed effects, week-of-sample fixed effects, and county-by-year fixed effects, in addition to controls for the ES certification status, and Energy Star rebates. In Specification II, we control for brand-week-of-sample and we interacted the county fixed effect with the Energy Star status. These Poisson regressions yield estimates that are lower than the OLS estimates but qualitatively the conclusions are the same. On average, there is a modest amount of undervaluation - the valuation ratio is $m=0.73$ for both specifications. This suggests that a linear model specification is not a significant biasing factor in our analysis. $^{8}$

\subsection{Sensitivity Analysis}

Table 7 shows the sensitivity of our energy cost responsiveness estimates to our assumptions driving lifetime energy costs. Specifically, we look at the effect of changing the discount rate

\footnotetext{
${ }^{7}$ We also show in Appendix A1 that using state rather than county average electricity prices to calculate energy costs has little effect on our estimates. Consistent with the 2SLS results, this suggests that measurement error in county-level prices is not a significant biasing factor in our analysis.

${ }^{8}$ Given the computational burden of the Poisson model, we use a $10 \%$ random sample for our estimation. In Appendix A2, we show that the OLS results for the full sample differ little from those using the $10 \%$ random sample.
} 
from 2 percent to 10 percent and the refrigerator lifetimes using values of 10, 15, 18, and 20 years. Using the coefficients from our preferred estimation (Specification IV) in Table 3, a discount rate of $5 \%$, and a lifetime of 18 years, the measure responsiveness to energy costs is $m=0.82$. This estimate is, however, highly sensitive to assumptions about the underlying parameters. Therefore, it is difficult to explicitly test the hypothesis of full responsiveness to

energy costs (i.e., $m=1$ ). While our baseline estimate of responsiveness is below 1 , a single percentage point change in the discount rate or a 2-3 year change in lifetime of the appliance can move the measure of energy cost responsiveness by as much as 20 percent. However, our estimates clearly show that on average consumers are responsive to energy operating costs using information about local electricity prices when purchasing an appliance.

\section{Conclusion}

This paper explores how shifts in retail prices and local electricity prices affect demand for appliances. We test if consumers respond to a measure of energy operating costs that relies on information about local electricity prices. We exploit a unique administrative data set from an appliance retailer, with individual transaction data tracking the price and location for each model sold. We compare the demand response from changes in the potentially misperceived energy costs to the demand response from changes in correctly perceived product prices. We estimate responsiveness to product price using exogenous variation created by the retailer's national pricing algorithm, which results in large and frequent model-specific price changes. We estimate responsiveness to energy costs using the relative differences in operating costs between more and less efficient models, which varies with electricity prices across space and time. We control for county-by-time specific movements in appliance demand to isolate the effect of energy operating costs from confounding market conditions, which might affect the probability of buying an appliance at all. 
We can strongly reject that consumers are unresponsive to local energy operating costs for appliances. The results from our preferred specification suggest that consumers are indifferent between $\$ 1.00$ in discount future energy costs, at a $5 \%$ discount rate and $\$ 0.82$ in purchase price. These results are surprising because the main energy information that is readily available in this decision context is provided by the EnergyGuide label, which only provides estimates of energy operating costs based on a national average. The Energy Star label is even coarser, and only provides a binary signal about energy efficiency. The fact that consumers do respond to a measure of local energy operating costs suggests that they have the ability to form complex beliefs beyond the pieces of information that are presented to them in the retail environment. These findings have implications beyond the energy context. The U.S. energy labels are examples of imperfectly targeted nudges. We show that consumers are able to overcome imperfect information in these labeling schemes, which suggests that they may be able to do so in other contexts as well.

Our results also have implications for our understanding of demand response to electricity prices. Capital investments are likely an important driver of the differences in short and long run elasticity estimates, since on average consumers are changing their appliance choices in response to local energy prices. These investments are an important margin to consider when designing energy and climate policies that bring electricity prices closer to the social cost of electricity. 


\section{References}

Abaluck, Jason and Jonathan Gruber, "Choice Inconsistencies Among the Elderly: Evidence from Plan Choice in the Medicare Part D Program," American Economic Review, 2011, 101 (4), 1180-1210.

Allcott, Hunt, "The Welfare Effects of Misperceived Product Costs: Data and Calibrations from the Automobile Market," American Economic Journal: Economic Policy, 2013, 5 (3), $30-66$.

and Cass R Sunstein, "Regulating Internalities," Journal of Policy Analysis and Management, 2015, 34 (3), 698-705.

and Christopher Knittel, "Are Consumers Poorly Informed about Fuel Econ-

omy? Evidence from Two Experiments," American Economic Journal: Economic Policy, 2019, forthcoming.

and Nathan Wozny, "Gasoline Prices, Fuel Economy, and the Energy Paradox," The Review of Economics and Statistics, 2014, 96 (5), 779-795.

Anderson, Soren T., Ryan Kellogg, and James M. Sallee, "What Do Consumers Believe About Future Gasoline Prices?," Journal of Environmental Economics and Management, 2013, 66, 383-403.

Auffhammer, Maximilian, "Energy Institute Blog: A Tale of Two Standards," https: //energyathaas. wordpress.com/2017/03/20/a-tale-of-two-standards/ 2017.

Barber, Brad M., Terrance Odean, and Lu Zheng, "Out of Sight, Out of Mind: The Effects of Expenses on Mutual Fund Flows," Journal of Business, 2005, 78 (6), 2095-2120.

Bollinger, Brian, Phillip Leslie, and Alan Sorensen, "Calorie Posting in Chain Restaurants," American Economic Journal: Economic Policy, 2011, 3 (1), 91-128.

Busse, Meghan, Christopher Knittel, and Florian Zettelmeyer, "Are Consumers Myopic? Evidence from New and Used Car Purchases," American Economic Review, 
2013, $103(1), 220-256$.

Campbell, John Y, Howell E Jackson, Brigitte C Madrian, and Peter Tufano, "Consumer Financial Protection," Journal of Economic Perspectives, 2011, 25 (1), 91-114.

Chetty, R., A. Looney, and K. Kroft, "Salience and Taxation: Theory and Evidence," American Economic Review, 2009, 99 (4), 1145-1177.

Davis, Lucas and Gilbert E. Metcalf, "Does Better Information Lead to Better Choices? Evidence from Energy-Efficiency Labels," Journal of the Association of Environmental and Resource Economists, 2016, 3 (3), 589-625.

Deryugina, T., Alexander MacKay, and Julian Reif, "The Long-Run Dynamics of Electricity Demand:Evidence from Municipal Aggregation," NBER Working Paper, 2017, (Number 23483).

Downs, Julie S, George Loewenstein, and Jessica Wisdom, "Strategies for Promoting Healthier Food Choices," American Economic Review, 2009, 99 (2), 159-64.

Dubin, J. and M. McFadden, "An Econometric Analysis of Residential Electric Appliance Holdings and Consumption," Econometrica, 1984, 52 (2), 345-362.

Finkelstein, A., "E-ztax: Tax Salience and Tax Rates," Quarterly Journal of Economics, 2009, 124, 969-1010.

Grigolon, Laura, Mathias Reynaert, and Frank Verboven, "Consumer Valuation of Fuel Costs and the Effectiveness of Tax Policy: Evidence from the European Car Market," American Economic Journal: Economic Policy: Forthcoming, 2018.

Guimaraes, Paulo and Pedro Portugal, "A Simple Feasible Procedure to Fit Models with High-Dimensional Fixed Effects," The Stata Journal, 2011, 10 (4), 628-649.

Handel, Benjamin R and Jonathan T Kolstad, "Health insurance for" humans": Information frictions, plan choice, and consumer welfare," American Economic Review, 2015, $105(8), 2449-2500$. 
Hausman, J., "Individual Discount Rates and the Purchase and Utilization of Energy Using Durables," Bell Journal of Economics, 1979, 10 (1), 220-225.

Hausman, Jerry A. and Paul L. Joscow, "Evaluating the Costs and Benefits of Appliance Efficiency Standards," American Economic Review Papers and Proceedings, 1982, 72 (2), 220-225.

Hossain, T. and J. Morgan, "Plus Shipping and Handling: Revenue (Non)Equivalence in Field Experiments on eBay," Advances in Economic Analysis and Policy, 2006, 6 (2).

Houde, Sébastien, "How Consumers Respond to Product Certification and the Value of Energy Information," RAND Journal of Economics, 2018, 49 (2), 453-477.

and Joseph E. Aldy, "Consumers' Response to State Energy Efficient Appliance Rebate Programs," American Economic Journal: Economic Policy, 2017, 9 (4), 227-255.

Ito, K., "Do Consumers Respond to Marginal or Average Price? Evidence from Nonlinear Electricity Pricing," American Economic Review, 2014, 104 (2), 537-563.

Jacobsen, G., "Do Energy Prices Influence Investment in Efficiency? Evidence from Energy Star Appliances," Journal of Environmental Economics and Management, 2015, 74 (C), 94-106.

Jensen, Robert, "The Perceived Returns to Education and the Demand for Schooling," Quarterly Journal of Economics, 2010, 125 (2), 515-548.

Kahn, M. and E. Mansur, "Do Local Energy Prices and Regulation Affect the Geographic Concentration of Employment?," Journal of Public Economics, 2013, 101, 105-114.

Kling, Jeffrey, Sendhil Mullainathan, Eldar Shafir, Lee Vermeulen, and Marian Wrobel, "Comparison Friction: Experimental Evidence from Medicare Drug Plans," Quarterly Journal of Economics, 2012, 127 (1), 199-235.

Mannix, Brian F and Susan E Dudley, "Please Don't Regulate my Internalities," Journal of Policy Analysis and Management, 2015, 34 (3), 715-718. 
Myers, E., "Are Home Buyers Inattentive? Evidence From Capitalization of Energy Costs," American Economic Journal: Economic Policy: Forthcoming, 2018.

Newell, Richard G. and J. Siikamaki, "Nudging Energy Efficiency Behavior: The Role of Information Labels," Journal of the Association of Environmental and Resource Economists, 2017, 1 (4), 555-598.

Rapson, D., "Durable Goods and Long-run Electricity Demand: Evidence from Air Conditioner Purchase Behavior," Journal of Environmental Economics and Management, 2014, 68 (1), 141-160.

Sallee, James M., "Rational Inattention and Energy Efficiency," Journal of Law and Economics, 2014, 57, 781-820.

Sallee, J.M., S. West, and W. Fan, "Do Consumers Recognize the Value of Fuel Economy? Evidence from Used Car Prices and Gasoline Price Fluctuations," Journal of Public Economics, 2016, 135, 61-73.

Wooldridge, J., Econometric Analysis of Cross Section and Panel Data, Second Edition, MIT Press, 2010. 


\section{Tables and Figures}

TABLE 1. Summary Statistics: Main Sample

\begin{tabular}{|c|c|c|}
\hline & Mean & S.D. \\
\hline Retail price $(\$)$ & 1263.33 & 620.26 \\
\hline Retail price inclusive of sales taxes $(\$)$ & 1348.95 & 662.75 \\
\hline Sales (qty/model-week-zip code) & 0.26 & 0.59 \\
\hline Electricity operating costs $(\$ /$ year $)$ & 60.87 & 20.10 \\
\hline Manufacturers' reported electricity use (kWh/year) & 516.77 & 79.16 \\
\hline Share of refrigerators $<29 \mathrm{cu} . \mathrm{ft} .(\%)$ & 48.75 & 49.99 \\
\hline Energy Star-certified (\%) & 70.36 & 45.68 \\
\hline Share of top-freezer (\%) & 25.27 & 43.46 \\
\hline \multicolumn{3}{|c|}{$\begin{array}{l}\text { Notes: Summary statistics (mean and standard deviation) for the main variables } \\
\text { used in the regressions. The overall sample has } 18,725,640 \text { unique combinations of } \\
\text { refrigerator models, weeks, and zip codes. The sample has } 2,520 \text { unique refrigerator } \\
\text { models during the period } 2008-2012 \text {. Electricity operating costs are computed } \\
\text { by multiplying average electricity prices at the county level and manufacturers' } \\
\text { reported estimates. }\end{array}$} \\
\hline
\end{tabular}


TABLE 2. Idiosyncratic Variation in Retail Prices

\begin{tabular}{lcccccc}
\hline \hline & I & II & III & IV & V & V \\
& & & & & & \\
\hline$\Delta$ Price w.r.t. Mean Price (\%) & 9.18 & 8.04 & 7.88 & 7.39 & 7.11 & 6.91 \\
$R^{2}$ & 0.965 & 0.973 & 0.974 & 0.977 & 0.979 & 0.980 \\
\hline Product FE & Yes & Yes & Yes & Yes & Yes & Yes \\
Week FE & No & Yes & No & No & No & No \\
Brand $\times$ Week FE & No & No & Yes & Yes & Yes & Yes \\
Energy Star $\times$ Week FE & No & No & No & Yes & Yes & Yes \\
EE Attributes $\times$ Week FE & No & No & No & Yes & Yes & Yes \\
County $\times$ Product FE & No & No & No & No & Yes & Yes \\
County $\times$ Brand $\times$ Week FE & No & No & No & No & No & Yes \\
\hline \hline
\end{tabular}

Notes: The dependent variable is the log of the retail prices. Each column reports the standard deviation of the residuals of a regression of the log of retail prices on various fixed effects ( $\Delta$ Price w.r.t. Mean). The residuals correspond to the percentage variation in retail prices relative to the mean price of each refrigerator model. The energy-related attributes (denoted "EE Attributes") other than Energy Star that we consider are a dummy variable that identifies small versus large full-size refrigerators and a dummy variable that distinguishes top-freezer versus other types of refrigerators. 
TABle 3. Estimation of the Effect of Price and Energy Costs on Demand

\begin{tabular}{lcccc}
\hline \hline & $\mathrm{I}$ & $\mathrm{II}$ & $\mathrm{V}$ & $\mathrm{VI}$ \\
\hline Purchase Price & $-0.000349^{* * *}$ & $-0.000349^{* * *}$ & $-0.000350^{* * *}$ & $-0.000360^{* * *}$ \\
& $(0.00000680)$ & $(0.00000672)$ & $(0.00000618)$ & $(0.00000664)$ \\
Annual Energy Cost & & & & \\
& $-0.00110^{* * *}$ & $-0.00387^{* * *}$ & $-0.00363^{* * *}$ & $-0.00343^{* * *}$ \\
& $(0.000166)$ & $(0.000388)$ & $(0.000402)$ & $(0.000399)$ \\
Valuation Ratio & & & & \\
& 0.268 & 0.948 & 0.888 & 0.816 \\
& $(0.042)$ & $(0.094)$ & $(0.096)$ & $(0.093)$ \\
\hline Product FE & & & & \\
County FE & Yes & Yes & Yes & Yes \\
Week FE & Yes & No & No & No \\
County $\times$ Year FE & Yes & Yes & Yes & Yes \\
County $\times$ Energy Star FE & No & Yes & Yes & Yes \\
County $\times$ EE Attributes FE & No & No & Yes & Yes \\
Brand $\times$ Week FE & No & No & No & Yes \\
$\#$ Observations & 18724399 & 18724399 & 18724399 & 18724395 \\
\hline \hline
\end{tabular}

Notes: The dependent variable is the number of units of a particular appliance sold in a given week in a given zip code. The standard errors are clustered at the county level and are in parentheses. $* * *, * *$ and $*$ denote statistical significance at the 1,5 and 10 percent levels. The valuation ratios are computed assuming a discount rate of $5 \%$ and a refrigerator lifetime of 18 years. 
TABLE 4. Robustness: Exogeneity of Retail Prices

\begin{tabular}{lcc}
\hline \hline & I & II \\
\hline Purchase Price & $-0.000328^{* * *}$ & $-0.000327^{* * *}$ \\
& $(0.00000625)$ & $(0.00000642)$ \\
Annual Energy Cost & $-0.00366^{* * *}$ & $-0.00351^{* * *}$ \\
& $(0.000412)$ & $(0.000397)$ \\
Valuation Ratio & & \\
& $(0.954$ & 0.919 \\
& & $(0.102)$ \\
\hline Product FE & Yes & Yes \\
County $\times$ Year FE & Yes & Yes \\
County $\times$ Energy Star FE & Yes & Yes \\
County $\times$ EE Attributes FE & Yes & Yes \\
Brand $\times$ Week FE & Yes & Yes \\
Energy Star $\times$ Week FE & Yes & Yes \\
Attribute $\times$ Week FE & No & 18724395 \\
$\#$ Observations & 18724395 & .
\end{tabular}

Notes: The dependent variable is the number of units of a particular appliance sold in a given week in a given zip code. The standard errors are clustered at the county level and are in parentheses. ${ }^{* * *}, * *$ and $*$ denote statistical significance at the 1,5 and 10 percent levels. The valuation ratios are computed assuming a discount rate of $5 \%$ and a refrigerator lifetime of 18 years. The 2SLS estimation uses the incidence of a promotion at the national level as an instrument. The first-stage results are presented in Table A1. 
TABLE 5. IV Estimation of the Effect of Price and Energy Costs on Demand

\begin{tabular}{lcc}
\hline \hline & I (OLS $)$ & II $(2 \mathrm{SLS})$ \\
\hline Purchase Price & $-0.000362^{* * *}$ & $-0.000362^{* * *}$ \\
& $(0.00000809)$ & $(0.00000809)$ \\
Annual Energy Cost & $-0.00350^{* * *}$ & $-0.00481^{* * *}$ \\
& $(0.000460)$ & $(0.000761)$ \\
& & \\
Valuation Ratio & 0.826 & 1.135 \\
& $(0.107)$ & $(0.178)$ \\
\hline Product FE & Yes & Yes \\
Brand $\times$ Week FE & Yes & Yes \\
County $\times$ Year FE & Yes & Yes \\
County $\times$ Energy Star FE & Yes & Yes \\
County $\times$ EE Attributes FE & Yes & 14790176 \\
$\#$ Observations & 14790176 & \\
\hline \hline
\end{tabular}

Notes: The dependent variable is the number of units of a particular appliance sold in a given week in a given zip code. The standard errors are clustered at the county level and are in parentheses. ${ }^{* *},{ }^{* *}$ and $*$ denote statistical significance at the 1,5 and 10 percent levels. The valuation ratios are computed assuming a discount rate of $5 \%$ and a refrigerator lifetime of 18 years. The first column is the OLS estimation with county electricity prices but restricted to the sample that we can implement the instrumental variable approach. The IV estimates are presented in the second column. We construct instruments for county-level energy price using the product of the local utility's capacity shares of coal, oil and gas-fired power plants and their respective annual average fuel price. We use data from EIA form 860 to construct the shares from 2007, the year before our sales data begin. We use the crude oil WTI spot price for petroleum plants, the annual Henry Hub contract 1 prices for natural gas plants, national average coal price from EIA for coal plants. The first-stage results are presented in Table A1. 
TABle 6. Estimation of the Effect of Price and Energy Costs on Demand: Poisson

\begin{tabular}{lcc}
\hline \hline & Poisson-I & Poisson-II \\
\hline Purchase Price & $-0.00224^{* * *}$ & $-0.00228^{* * *}$ \\
& $(0.0000420)$ & $(0.0000448)$ \\
Annual Energy Cost & $-0.0191^{* * *}$ & $-0.0195^{* * *}$ \\
& $(0.00170)$ & $(0.00173)$ \\
& & \\
Valuation Ratio & 0.731 & 0.731 \\
& $(0.064)$ & $(0.063)$ \\
& & \\
Product FE & Yes & Yes \\
Week of Sample FE & Yes & Yes \\
Brand $\times$ Week FE & No & Yes \\
County $\times$ Energy Star FE & No & 1850810 \\
$\#$ Observations & 1869985 & \\
\hline \hline
\end{tabular}

Notes: These models are estimated using a $10 \%$ random subsample from our full data set. The dependent variable is the number of units of a particular appliance sold in a given week in a given zip code. The standard errors are clustered at the county level and are in parentheses. $* * *, * *$ and $*$ denote statistical significance at the 1,5 and 10 percent levels. The valuation ratios are computed assuming a discount rate of $5 \%$ and a refrigerator lifetime of 18 years. 
TABLE 7. Sensitivity of Valuation Raio Estimates to Parameter Assumptions

\begin{tabular}{ccccc}
\hline \hline Discount Rate & 10 Year Lifetime & 15 Year Lifetime & 18 Year Lifetime & 20 Year Lifetime \\
\hline 2 percent & 1.061 & 0.742 & 0.636 & 0.583 \\
3 percent & 1.117 & 0.798 & 0.693 & 0.640 \\
4 percent & 1.175 & 0.857 & 0.753 & 0.701 \\
5 percent & 1.234 & 0.918 & 0.815 & 0.765 \\
6 percent & 1.295 & 0.981 & 0.880 & 0.831 \\
10 percent & 1.551 & 1.253 & 1.162 & 1.119 \\
\hline \hline
\end{tabular}

Notes: This table shows the ratio of demand responsiveness to a $\$ 1$ change in lifetime energy costs relative to a $\$ 1$ change in upfront price calculated for discount rates of 2 percent, 3 percent, 4 percent, 5 percent, 6 percent, and 10 percent and for refrigerator lifetimes of 10, 15, 18, and 20 years. We use the coefficient estimates on purchase price and annual energy cost from Specification IV in Table 3. 


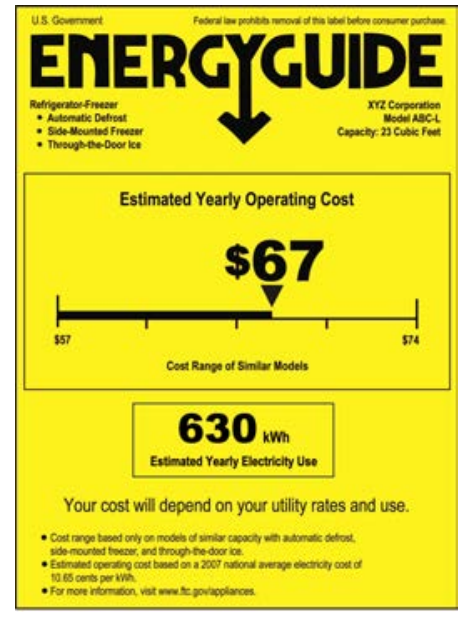

(a) EnergyGuide Label (2007 version)

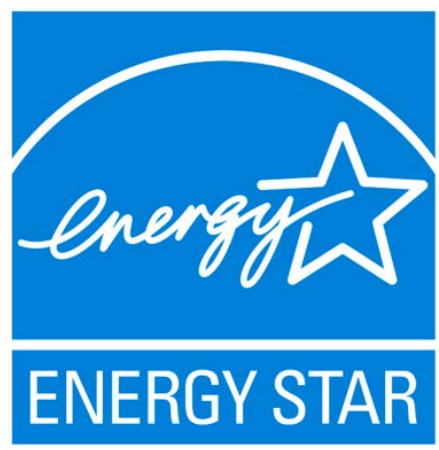

(b) Energy Star Label

FiguRE 1. Energy Labels: U.S. Appliance Market 


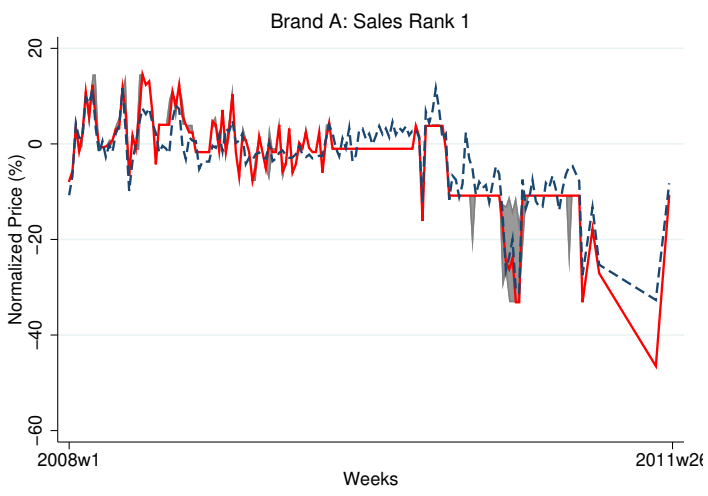

(a)

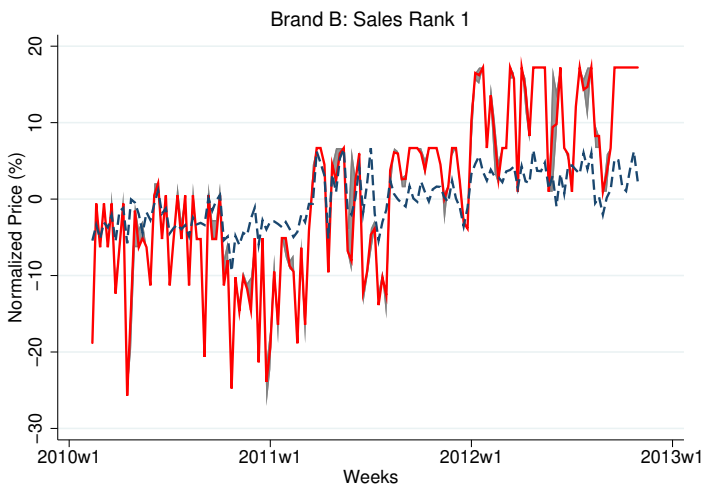

(c)

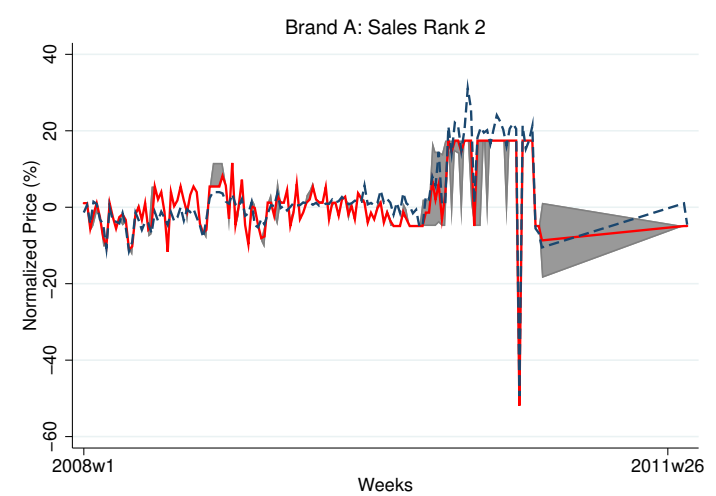

(b)

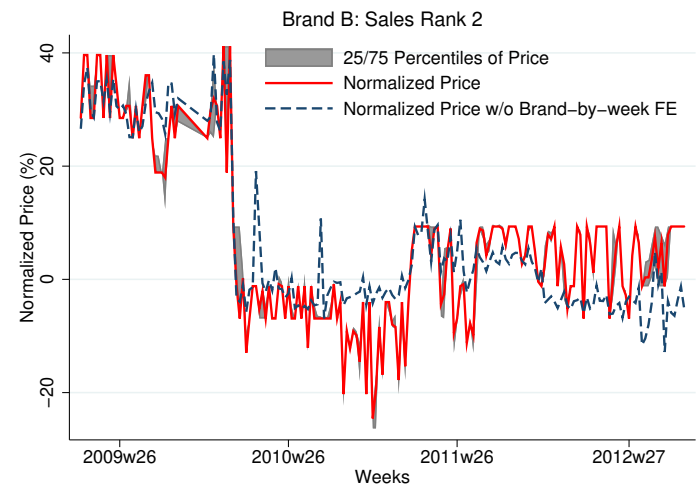

(d)

\section{Figure 2. Price Variation Due to Retailer's National Pricing Algorithm}

Notes: Each panel corresponds to a particular model offered by a particular brand. Models with sales rank equals to one corresponds to the most popular model offered by a given brand. Each panel displays the week-to-week variation in retail price relative to the mean price for a particular model. The plain red line corresponds to the median price across zip codes. The grey band depicts the $25^{t h}$ and $75^{t h}$ percentiles. The dash blue line is the median price without brand-by-week fixed effects. 

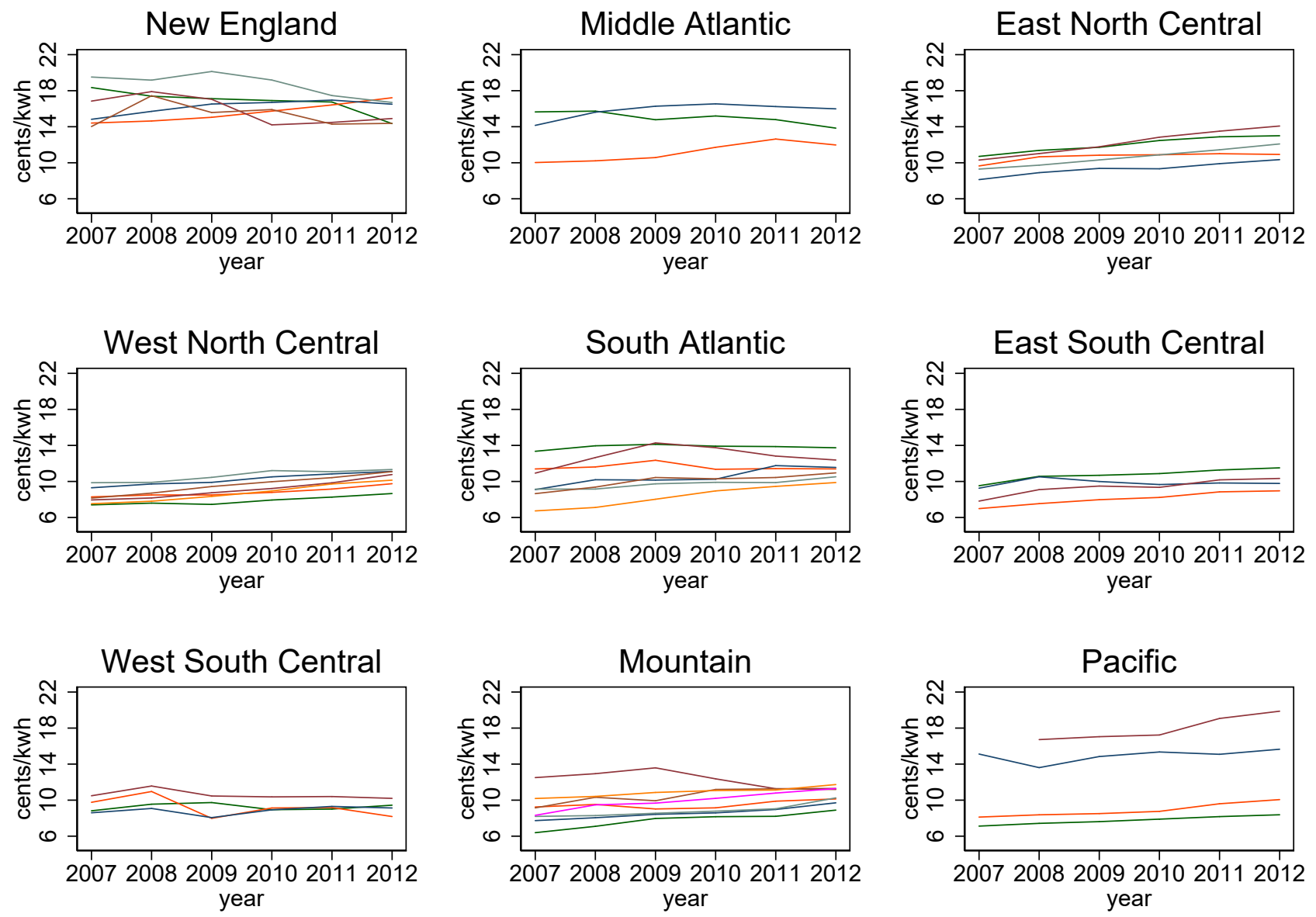

Figure 3. Average Electricity Prices for Each State in a Census Division

Notes: Each line represents the appliance sales weighted average electricity price for a particular state within each census division. 

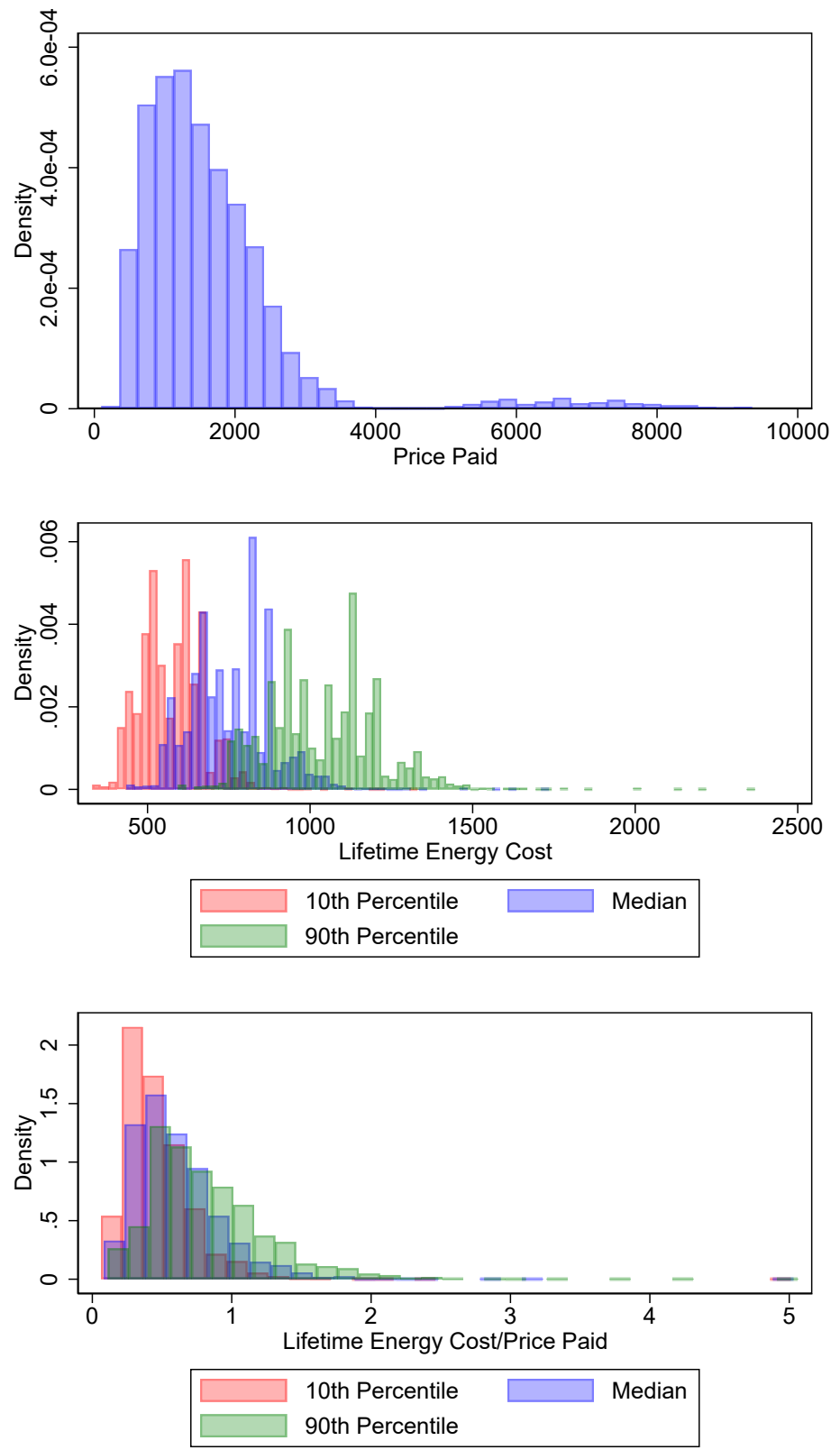

Figure 4. Distributions of Prices and Lifetime Energy Costs

Notes: The lifetime energy costs are calculated using, an expected lifetime of 18 years, and a discount rate of $5 \%$, and the manufacturer's reported annual energy consumption for each model at the 10th, 50th, and 90th percentile of electricity prices. 


\section{Appendix}

\section{For Online Publication}

\section{A1. Robustness to Model Specification}

Table A2 displays the results from including county-by-week fixed effects rather than countyby-year fixed effects, as we use in our preferred specification. Specification I is comparable to Specification II in Table 3 in that the only difference is time dimension that we interact with the county fixed effects. There is little difference in the coefficients on purchase price and annual energy cost and in the responsiveness to energy costs parameter. This is unsurprising given that we are exploiting annual variation in electricity prices, so that the identifying

variation in both cases is the differences in relative energy costs between low and high consuming refrigerators for low and high electricity price county-year combinations.

Specification II is our preferred specification using state average electricity prices rather than county average electricity prices. The results differ little depending on which level of aggregation is used. Consistent with our 2SLS exercise, it appears that measurement error in county level prices is not a significant biasing factor in our analysis.

\section{A2. OLS with Zip Code-Level Controls}

Table A3 displays the results from where we use control for zip code level unobservables. We use the exact same specifications as in Table 3, except that we include zip code fixed effects interacted with various controls, i.e., time dummies or attributes. There is little difference in the coefficients on purchase price and annual energy cost and in the responsiveness to energy costs parameter. 


\section{A3. OLS Results Using a 10\% Random Sample}

Table A4 shows the results for our preferred specification using the $10 \%$ subsample rather than the full sample. There is little difference in our coefficient estimates or energy cost responsiveness parameter when using a 10\% subsample. Therefore, the comparisons between our Poisson estimates and OLS estimates should not be affected by the fact that we used a subsample to estimate the Poisson regressions.

\section{Appendix Tables}

TABLE A1. First-Stage: IV Regression

\begin{tabular}{lc}
\hline \hline dep. var. & county electricity prices \\
\hline IV: capacity share $\times$ fuel prices & $38.44^{* * *}$ \\
& $(7.824)$ \\
F stats & 25.27 \\
$\mathrm{R}^{2}$ & 0.9970 \\
\hline Product FE & Yes \\
County $\times$ Year FE & Yes \\
County $\times$ Energy Star FE & Yes \\
County $\times$ EE Attributes FE & Yes \\
Brand $\times$ Week FE & Yes \\
$\#$ Observations & 14790176 \\
\hline \multicolumn{2}{l}{ Notes: First-stage regression for the instrumental variable } \\
approach presented in the main text. \\
\hline \hline
\end{tabular}


TABLE A2. OLS Regressions: Additional Robustness Checks

\begin{tabular}{lcc}
\hline \hline & I & II \\
\hline Purchase Price & $-0.000346^{* * *}$ & $-0.000360^{* * *}$ \\
& $(0.00000674)$ & $(0.00000663)$ \\
Annual Energy Cost (County) & $-0.00395^{* * *}$ & \\
& $(0.000399)$ & \\
& & \\
Annual Energy Cost (State) & & $-0.00371^{* * *}$ \\
& & $(0.000333)$ \\
Valuation Ratio & 0.974 & \\
& $(0.098)$ & 0.881 \\
& & $(.078)$ \\
\hline Product FE & Yes & Yes \\
County FE & No & Yes \\
Week FE & No & Yes \\
County $\times$ Year FE & No & No \\
County $\times$ Week FE & Yes & Yes \\
County $\times$ Energy Star FE & No & Yes \\
County $\times$ EE Attributes FE & No & Yes \\
Brand $\times$ Week FE & No & 18724395 \\
$\#$ Observations & 18724142 & \\
\hline \hline
\end{tabular}

Notes: The dependent variable is the number of units of a particular appliance sold in a given week in a given zip code. The first column uses a measure of electricity operating costs based on county average electricity prices and the second column is based on state electricity prices. The standard errors are clustered at the county level and are in parentheses. $* * *, * *$ and $*$ denote statistical significance at the 1 , 5 and 10 percent levels. The valuation ratios are computed assuming a discount rate of $5 \%$ and a refrigerator lifetime of 18 years. 
TABle A3. OLS Regressions: Additional Robustness Checks

\begin{tabular}{|c|c|c|c|c|}
\hline & $\overline{I I}$ & II & III & IV \\
\hline Appliance Price & $\begin{array}{c}-0.000350^{* * *} \\
(0.00000689)\end{array}$ & $\begin{array}{c}-0.000350^{* * *} \\
(0.00000682)\end{array}$ & $\begin{array}{l}-0.000350^{* * *} \\
(0.00000630)\end{array}$ & $\begin{array}{c}-0.000360^{* * *} \\
(0.00000676)\end{array}$ \\
\hline Annual Energy Cost & $\begin{array}{c}-0.00110^{* * *} \\
(0.000167)\end{array}$ & $\begin{array}{c}-0.00390^{* * *} \\
(0.000391)\end{array}$ & $\begin{array}{c}-0.00368^{* * *} \\
(0.000408)\end{array}$ & $\begin{array}{r}-0.00348^{* * *} \\
(0.000407)\end{array}$ \\
\hline Valuation Ratio & $\begin{array}{c}0.269 \\
(0.043)\end{array}$ & $\begin{array}{c}0.954 \\
(0.095)\end{array}$ & $\begin{array}{c}0.899 \\
(0.098)\end{array}$ & $\begin{array}{c}0.826 \\
(0.096)\end{array}$ \\
\hline Product FE & Yes & Yes & Yes & Yes \\
\hline Zip Code FE & Yes & No & No & No \\
\hline Week FE & Yes & Yes & Yes & Yes \\
\hline Zip code $\times$ Year FE & No & Yes & Yes & Yes \\
\hline Zip code $\times$ Week FE & No & No & No & No \\
\hline Zip code $\times$ Energy Star FE & No & No & Yes & Yes \\
\hline Zip code $\times$ EE Attributes FE & No & No & Yes & Yes \\
\hline Brand $\times$ Week FE & No & No & No & Yes \\
\hline \# Observations & 18724399 & 18724399 & 18724399 & 18724395 \\
\hline
\end{tabular}

Notes: The dependent variable is the number of units of a particular appliance sold in a given week in a given zip code. The standard errors are clustered at the county level and are in parentheses. ***, ** and * denote statistical significance at the 1, 5 and 10 percent levels. The valuation ratios are computed assuming a discount rate of $5 \%$ and a refrigerator lifetime of 18 years. 
TABle A4. Estimation of the Effect of Price and Energy Costs on Demand: $10 \%$ Sample

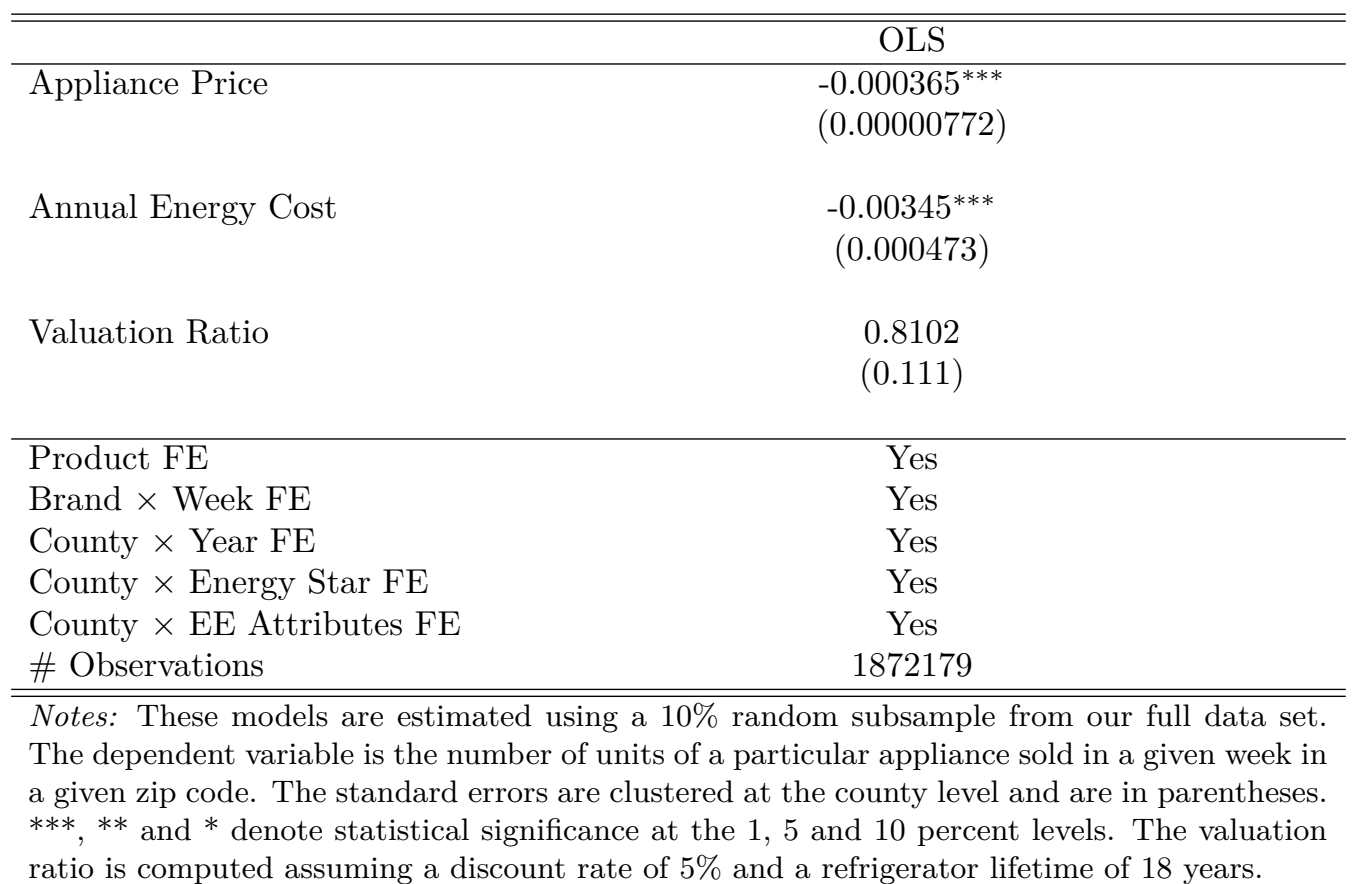

